\title{
Hearing loss in the elderly: History of occupational noise exposure
}

\author{
Caroline Luiz Meneses-Barriviera', Juliana Jandre Melo², Luciana Lozza de Moraes Marchiori³.
}

\author{
1) Master degree (Rehabilitation Sciences), UEL Universidade Estadual de Londrina Universidade Norte do Paraná UNOPAR). \\ 2) Master degree (Speech-Language and Hearing Pathology), Pontifícia Universidade Católica PUC/SP (UNOPAR). \\ 3) Ph.D. (Medicine and Health Sciences), UEL (UNOPAR) \\ Institution: Universidade Norte do Paraná (UNOPAR) \\ Londrina / PR - Brazil. \\ Mailing address: Juliana Jandre Melo - Campus Universitário de Londrina - Clinica de Fonoaudiologia - Av. Paris, 675 - Jd. Piza - Londrina / PR - Brazil - Zip code \\ 86041-140 - Cx. P. 401 - E-mail: juliana.melo@unopar.br \\ Article received on August 22, 2012. Article accepted on February 18, 2013
}

\section{SUMMARY}

Introduction: Noise exposure is one of the most common health risk factors, and workers are exposed to sound pressure levels capable of producing hearing loss.

Aim: To assess the prevalence of hearing loss in the elderly and its possible association with a history of occupational noise exposure and with sex.

Methods: A prospective study in subjects aged over 60 years. The subjects underwent anamnesis and audiological assessment. The Mann-Whitney test and multiple logistic regression, with 95\% confidence interval and $\mathrm{p}<0.05$, were used for statistical analysis.

Results: There were 498 subjects from both sexes, and the median age was 69 years. From the comparison between men and women, we obtained the medium hearing I (500, 1000, and $2000 \mathrm{~Hz} p=0.8318)$ and the mean hearing II (3000, 4000, and $6000 \mathrm{~Hz} ; \mathrm{p}<0.0001)$. Comparing the thresholds of individuals with and without a history of occupational noise exposure, we obtained the medium hearing I $(p=0.9542)$ and the mean hearing II $(p=0.0007)$.

Conclusion: There was a statistically significant association between hearing loss at high frequencies and the risk factors being male and occupational noise exposure.

Keywords: Hearing Loss; Noise; Aged.

\section{INTRODUCTION}

Recent research has determined that the current average life expectancy is increasing and is linked to a gradual decrease in mortality rates and birth rates (1-3). Population aging is a global phenomenon. It is likely that the number of people over 60 years will increase over $300 \%$ over the next 50 years, from 606 million in 2000 to approximately 2 billion in 2050, of which 1.6 billion will come from under developed countries and developing countries, and to which Brazil would contribute 58 million (4).

In Brazil, data obtained by the national survey of households conducted in 2006 Instituto Brasileiro de Geografia e Estatística (IBGE) stated that the elderly population in Brazil is increasing, and will exceed 30 million people in 20 years, representing about $13 \%$ of the population (3,5-9).

Audiology is one of the fields contributing to the prevention and treatment of changes from aging as an attempt to meet the demands of the aging population and improving their quality of life $(2,10)$.
The fact that life expectancy has increased does not mean that living conditions for the elderly also have improved (3). Already suffering from sensory changes, hearing impairment is a major cause of social isolation for the elderly, and hearing loss appears to be the change that leaves the greatest impact on communication $(6,11)$.

Hearing loss is the third most prevalent chronic condition among older people behind arthritis and hypertension, and there is a slight tendency for the prevalence to be higher in men than in women $(2,12)$.

According to the American Speech-Language Hearing Association (ASHA) (13), 28 million individuals in the United States currently have some hearing loss, and it is irreversible in $80 \%$ of them. The ASHA has also shown that $54 \%$ of the over- 65 population has some hearing loss.

Noise exposure is one of the most common health risk factors. Millions of laborer workers worldwide are exposed to sound pressure levels capable of producing hearing loss (14). This occupational exposure to loud noise can damage the hair cells of the organ of Corti, causing 
progressive and irreversible hearing loss, a condition known as noise-induced hearing loss (NIHL) (15).

NIHL is a permanent change in the hearing threshold caused by acoustic trauma; it is chronic and characterized as sensorineural, usually bilateral and symmetrical, mild at low frequencies and severe at high frequencies, with typical audiometric configuration (slot-shaped $\mathrm{V}$ ) in the 6000, 4000, and/or 3000-Hz frequency range, which progresses slowly at other frequencies and reaches its maximum level at higher frequencies within the first 1015 years of stable exposure to high sound pressure levels $(15,16)$. The progression of hearing loss ceases when the exposure to the noise stops, but the damage caused is irreversible. Tinnitus has also been recognized as a highpitched auditory effect of NIHL (16).

Studies have found that auditory acuity declines significantly with age in both men and women, being more frequent in men (17-24). Regarding sex, Bilton et al. (18) concluded that there were no statistically significant differences between men and women.

Therefore, the purpose of this study was to determine the prevalence of hearing loss in the elderly and its possible association with a history of working in a noisy environment and with sex.

\section{Methods}

This was a cross-sectional population-based study for which project approval (PP/0063/09) was received from the ethics committee. The subjects signed an informed consent form according to the resolution 196/96-CNS.

The study involved men and women aged over 60 years who lived independently and who were classified at levels 3 and 4 of the Functional Status Spirduso proposed by (25) and who agreed to participate voluntarily in the study. The participants were registered at 38 BHUs in the urban area of Londrina, Paraná. The sample was randomly stratified, taking into account the 5 regions of the municipality. From a population of 43,610 seniors enrolled at the 38 BHUs, the sample was calculated to comprise 385 people ideally, and considering the probable losses in the population, the eventual sample was large, comprising 519 individuals: $15 \%, 27 \%, 23 \%, 19 \%$, and 16\% were from the central, northern, southern, eastern, and western regions, respectively. A sampling error of $5 \%$ was considered for the calculations.

We evaluated all 519 subjects, excluding those who did not participate in the audiometric testing and reducing the sample to 498 subjects.
The diagnostic evaluation of hearing consisted of audiological methods used in routine audiology care and was based on the Katz protocol for anamnesis (26), followed by pure tone audiometry, considered the gold standard for evaluating the hearing threshold in adults, which is recorded for all of the audiometry used in routine audiology care and inserted in the database program WinAudio to be stored and printed for the patient.

The dependent variable was the presence of sensorineural hearing loss. The independent variables were sex and history of working in a noisy environment. The variables are descriptively presented as absolute numbers and proportions, estimating the prevalence.

As the criteria for hearing loss, we used the classification of Davis and Silverman (27) to analyze the mean hearing I (500, 1000, and $2000 \mathrm{~Hz})$, and that of the National Committee on Noise (28) and Amorim et al. (29) to analyze the medium hearing II (3000, 4000, and 6000 $\mathrm{Hz}$ ). The classification used was the degree of hearing loss: mild, 26-40 dB; moderate, 41-70 dB; severe, 71-90 dB; profound, $>91 \mathrm{~dB}$ (27).

Study The Mann-Whitney test was used to check for possible differences between the risk factors and individuals with and without hearing loss, and logistic regression was used to determine the independent risk factors for hearing loss. The tests were performed using the Bio software Biostat 5.0.

For univariate analysis and inclusion in the final model for the statistical tests, we considered $p<0.05$ and the $95 \%$ confidence interval.

\section{RESULTS}

This study evaluated 519 subjects of both sexes. The individuals who did not attend the audiometric test were excluded, leaving 498 subjects.

Of these, 332 (66.66\%) were women and 166 (33.33\%) were men; the median age was 69 years. Of these 498 subjects, 91.56\% (456 subjects) had bilateral hearing loss and $8.43 \%$ ( 42 subjects) had unilateral hearing loss. Based on evaluation of the degree of hearing loss, 26.50\%, 12.75\%, 1.6\%, and 0.7\% had mild, moderate, severe, and deep hearing loss, respectively, while $58.43 \%$ had normal hearing or had decreased hearing acuity at $6000 \mathrm{~Hz}$ and $8000 \mathrm{~Hz}$ (27).

The D'Agostino-Pearson test was used to test the normality of the data. As the data did not exhibit a normal distribution, we used the Mann-Whitney test to compare 
Table I. Multiple logistic regression and independent risk factors for hearing loss.

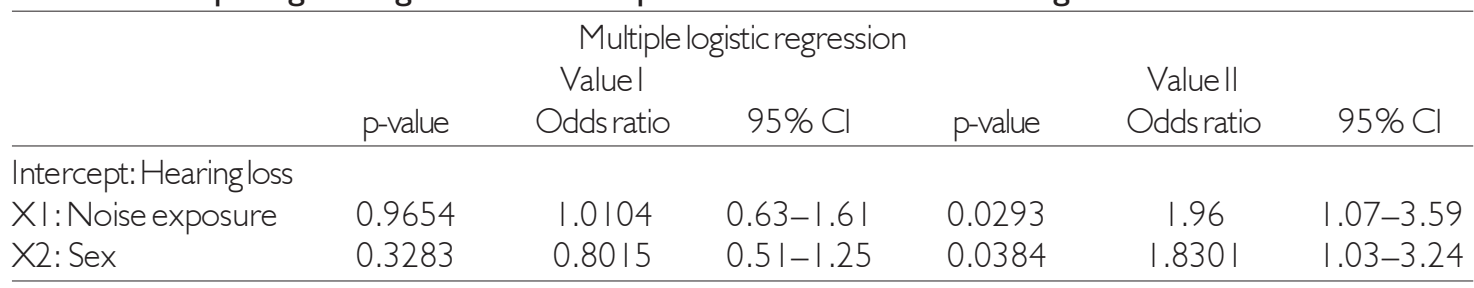

the mean hearing I (500, 1000, and $2000 \mathrm{~Hz})$ and II (3000, 4000 , and $6000 \mathrm{~Hz}$ ) obtained through audiometry and other collected data.

Checking the data for average hearing, we observed no statistically significant difference between the right and left ears: mean hearing I $(\mathrm{p}=0.3294)$ and medium hearing II ( $p=0.9295)$; therefore, we used the data from the right ear as the standard.

When the men and women were compared, we determined mean hearing I $(\mathrm{p}=0.8318)$ and medium hearing II $(\mathrm{U}=27234.5)$, and the mean $(\mathrm{p}<0.0001)$ and $(\mathrm{U}=19604)$.

Comparing the average hearing of the 497 subjects who completed the questionnaire on hearing care (one was excluded for not having answered the questionnaire), $134(26.90 \%)$ and $363(72.89 \%)$ individuals with and without a history of occupational noise exposure, respectively, had medium hearing $\mathrm{I}(\mathrm{p}=0.9542$ and $\mathrm{U}=$ 24420.5), and medium hearing II ( $\mathrm{p}=0.0007$ and $\mathrm{U}=$ 19663). To verify the independent risk factors for hearing loss, we performed multiple logistic regression, obtaining the results listed in Table 1.

Thus, statistical analysis determined that both the variables sex (hearing loss was more prevalent in males) and history of occupational noise exposure were associated with hearing loss at high frequencies in older people, and according to the multiple logistic regression, both were independent risk factors for hearing loss. The subjects who were exposed to occupational noise were 1.96 times more likely to develop hearing loss at high frequencies compared to those who were not. The men were 1.8301 times more likely to develop hearing loss than the women were.

\section{DISCUSSION}

The aim of preserving low-frequency hearing acuity in the elderly led to the need for a classification based on broader frequency bands in order to better characterize the decrease in hearing thresholds (30-31). Statistical analysis was performed on mean hearing I (500, 1000, and 2000
$\mathrm{Hz})(27)$ and II (3000, 4000, and $6000 \mathrm{~Hz})(28-30)$ to analyze the hearing loss characteristics of the study population properly.

Regarding sex, this study recorded a higher prevalence of hearing loss in medium hearing II and in men $(\mathrm{p}<0.0001)$. Other studies have highlighted the increased frequency of hearing loss in men $(32,33)$ as well as that the decline is greatest from $3000 \mathrm{~Hz}$ (2.34-36), and in agreement with the finding that hearing loss prevalence is higher in men, have suggested that this is possibly due to the higher level of noise exposure in men as well. We also corroborated our results in relation to sex by investigating the decline in hearing threshold at the ages most frequently reported for men (17.19-24 years). The multiplicity of the metabolic and circulatory changes related to noise can lead to the appearance of various symptoms, including slowonset and progressive hearing loss $(37,38)$.

In this study, there was a statistically significant association between hearing loss at high frequencies and noise exposure (mean hearing I, $\mathrm{p}=0.9542$ and medium II, $p=0.0007)$. NIHL is the second most common form of sensorineural hearing deficit after presbycusis (37).

The possible correlations between age and a history of occupational noise exposure in the elderly paints a complex picture due to the variety of factors associated with age. It is difficult to determine whether the hearing loss in the elderly is caused only by the degeneration associated with age $(37,39)$.

Noise exposure represents about $10 \%$ of the burden of hearing loss in adults in the United States; most of the remainder is related to age. Most of the burden of occupational noise is attributable to unprotected exposure above $95 \mathrm{~dB}$, becoming apparent in middle age when the noise exposure has ceased and age-related changes come into play, resulting in clinically significant impairment (40).

From these results, we conclude that being male and occupational noise exposure are the risk factors that predispose a person to hearing loss at high frequencies, especially when associated with presbycusis, and are independent factors for hearing impairment. 
It is hoped that these data may contribute to health prevention strategies, publicize the risks of occupational noise exposure to the development of hearing loss, and encourage the periodic monitoring of hearing health in the elderly. Prophylactic measures to compensate for aging may also help to control hearing loss and decrease the psychosocial impact of hearing loss in these individuals.

\section{CONCLUSION}

There was a statistically significant association between hearing loss at high frequencies, and the risk factors were being male and occupational noise exposure. These were also the independent risk factors for hearing loss.

\section{REFERENCES}

1. Baraldi GS, Almeida LC, Borges ACC. Hearing loss in aging. Braz J Otorhinolaryngol. 2007;73(1):64-70.

2. Greco MC, Russo ICP. Audiological findings of elderly individuals of a private clinic in são paulo city. Acta ORL. 2006; 24(4):245-54.

3. Meneses C, Mário MP, Marchiori LLM, MeloJJ, Freitas ERFS. Prevalence of hearing loss and associated factors in elderly population in Londrina, Paraná: preliminary study. CEFAC. 2010;12(3):384-92.

4. Scazufca M, Cerqueira ATAR, Menezes PR, Prince M, Vallada HP, Miyazaki MCOS. Epidemiological research on dementia in developing countries. Saúde Publica. 2002;36(6):773-8.

5. Carmo LC, Silveira JAM, Marone SAM, D'Ottaviano FG, ZagatiLL, Lins EMDS. Audiological study of an elderly brazilian population. Braz J Otorhinolaryngol. 2008;74(3): 342-49.

6. Nobrega JD, Câmera MFS, Borges ACC. Hearing in the elderly: Analysis of the perception of hearing loss, audiological profile and their correlations. RBPS. 2008;21(1):

39-46.

7. Veras RP, Mattos LC.Audiology and aging: literature review and current horizons. Braz J Otorhinolaryngol. 2007;73(1):128-34.

8. IBGE [Internet]. [cited 2009 Aug 18]. Available from: www.ibge.com.br.

9. Silva BSR, Sousa GB, Russo ICP e Silva JAPR.
Characterization of the complaints, kind of hearing loss and treatment for elderly people seen at a private clinic in Belem - PA. Arq. Int. Otorrinolaringol. 2007;11(4):387-95.

10. Agrawal Y, Platz EA, Niparko JK. Risk factors for hearing loss in US adults: data from the National Health and Nutrition Examination Survey, 1999 to 2002. Otol Neurotol. 2009;30(2):139-45.

11. Russo IP. Speech therapy in elderly. Revinter: Rio de Janeiro; 2004.

12. Valete R, Cláudia M, Rozenfeld S. Auditory screening in the elderly: comparison between self-report and audiometry. Braz J Otorhinolaryngol. 2005;71(2):193-200.

13. ASHA (American Speech, Language and Hearing Association) [Internet]. [cited 2008 Sep 20]. Available from: www.asha.org.

14. Souza NSS, Carvalho FM, Fernandes RC. Arterial hypertension among oil-drilling workers exposed to noise. Cad. Saúde Pública. 2001;17(6):1481-88.

15. Dias RC, Cordeiro R, Corrente JE, Gonçalves CGO. Association between noise induced hearing loss and tinnitus. Cad. Saúde Pública. 2006;22(1):63-8.

16. Teles RM, Medeiros MPH. Audiometric profile of Maracanaú's industrial district workers. Rev. Soc. Bras. Fonoaudiol. 2007;12(3):233-9.

17. Russo ICP. Uso de próteses auditivas emidosos portadores de presbiacusia: indicação, adaptação e efetividade. Use of hearing aids in elderly people with presbycusis: indication, adjustment and effectiveness [dissertation]. [São Paulo]: Escola Paulista de Medicina; 1988.

18. Bilton T, Ramos LR, Ebel S, Teixeira LS, Tega LP. Audiological Study of the 'Profile of Individuals Attended in the Brazilian Diagnostic Service. 1997;21(4):218-25.

19. Sousa MGC, Russo ICP.Hearing and perception of hearing loss in elderly people. Rev Soc Bras de Fonoaudiol. 2009; 14(2):241-46.

20. Corso JF. Presbycusis, hearing aids and aging. Audiology . 1977;16(2):146-63.

21. Hull RH. Hearing in aging. San Diego, CA: Singular Publishing Group, INC.; 1995.

22. Bess FH, Hedley-Williams A, Lichtenstein MJ. In: Perspectivas atuais em avaliação auditiva. São Paulo: Manole; 2001. p. 343-64. 
23. Gates GA, Cooper JC. Incidence of hearing decline in the elderly. Acta Otolaryngol. 1991;111(2):240-48.

24. Bess FH, Humes LE. Pathologies of the auditory system. In: Fundamentos em audiologia. 2nd ed. Porto Alegre: Artmed; 1998. p. 155-95.

25. Spidurso WW. Physical Dimensions of Aging. Barueri: Manole; 2005.

26. KatzJ.Handbookof Clinical Audiology. São Paulo: Manole; 1989.

27. Davis H, Silverman SR. Hearing and deafness. 3rd ed. New York: Holt, Rinehart and Winston; 1970.

28. National Committee on Noise and Hearing Conservation Recommendations for the assessment of damage caused by Noise Induced Hearing Loss, Carta aos editores, Acta AWHO. 1996, 16:45.

29. Amorim RB, Lopes AC, Santos KTP, Melo ADP, Lauris JRP. Auditory Alterations for Occupational Exposition in Musicians. Arq. Int. Otorrinolaringol. 2008;12(3):377-83.

30. Marchiori LLM, Rego FEA, Matsuo T. Hypertension as a factor associated with hearing loss. Braz J Otorhinolaryngol. 2006; 72(4):533-40.

31. Kano CE, Mezzena LH, Guida HL.Comparative study for classifying the hearing loss degree in institutionalized elderly. Rev. CEFAC. 2009;11(3):473-7.

32. Baraldi GS, Almeida LC, Borges ACC. Hearing loss and hypertension: findings in an older by group. Rev Bras de Otorrinolaringol. 2004;70(5):640-4.

33. Momensohn-Santos TM, Russo IP, editors. Clinical audiology. 6th ed. São Paulo: Cortez; 2007.

34. Bess FH, Hedley-Williams A, Lichtenstein MJ. Audiological assessment in elderly. In: Musiek FE, Rintelmann MJ. Current perspectives in hearing assessment. São Paulo: Manole; 2001. p. 343-69.

35. Lopes Fo O. Hearing loss. In: Lopes Fo O, Campos CAH. Otolaryngology. São Paulo: Roca; 1994. p. 531-44.

36. Gates GA, Cooper JC, William BK, Miller NJ. Hearing in the elderly: The Framingham Cohort, 1983-1985. Part I. Basic Audiometric Test Results. Ear Hear. 1990;11(4):247-56.

37. MarchioriLLM, MeloJJ, Meneses CL. Comparison of hearing loss in Elderly with and without history of occupational noise exposure. Proceeding of the 10th International Congress on Noise as a Public Health. London; 2011.

38. Daniel E. Noise and hearing loss: a review. J Sch Health. 2007;77(5):225-31.

39. Poli-Frederico RC, Marchiori LLM, Melo JJ, Carvalho LL. Possible identification of Noise-Induced Hearing Loss susceptibility genes. Proceeding of the 10th International Congress on Noise as a Public Health. London; 2011.

40. Dobie RA. The burdens of age-related and occupational noise-induced hearing loss in the United States. Ear Hear. 2008;29(4):565-77. 